\title{
Nodal network and CFD simulation of airflow and heat transfer in double skin facades with blinds
}

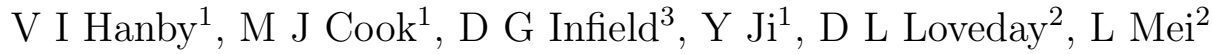

1. Institute of Energy and Sustainable Development

De Montfort University

The Gateway

Leicester LE1 9BH, UK.

(+)44116257 7980 vhanby@dmu.ac.uk (corresponding author)

2. Department of Civil and Building Engineering

Loughborough University

Loughborough LE11 3TU UK

3. Centre for Renewable Energy Systems Technology

Department of Electronic and Electrical Engineering

Loughborough University

Loughborough LE11 3TU UK

\begin{abstract}
The paper describes a modeling study of heat transfer and buoyancy-driven airflow in double skin facades consisting of a glass outer layer, a control device (venetian blind) and a double-glazed inner skin. The modeling study was based on two approaches - a component-based, lumped parameter simulation which used a public domain, open source differential/algebraic equation solver and a detailed, CFD calculation which included air flow, conduction, convection and radiation. The primary objective of the work was to compare the performance of the simplified model with the output of a rigorous CFD calculation.

A library of basic component models was developed, enabling a flexible approach to be taken to the assembly of system models. The coupling of heat transfer processes with buoyancy-driven air flow was facilitated by the use of an equation-based simulation methodology. Simulation output was compared to experimental results obtained from a prototype section of facade, the performance of which had been characterised in a climatically-controlled solar simulator.
\end{abstract}

\section{INTRODUCTION}

Multifunctional (double) facades increasingly feature in the design of commercial buildings. These facades generally incorporate a solar control device (usually a venetian blind) within the cavity which affects the transmission of solar gain to the space and also the generation of buoyancydriven flows within the cavity. Double skin facades can contribute a heat gain in winter, or drive a ventilation air flow when cooling may be required. Whilst there has been considerable research carried out on the performance of such facades (a good summary has been given by Fux 2006), modeling studies have, in general, not looked in detail at the combination of heat transfer and buoyancy-driven flow. 
The interaction of heat transfer and fluid flow can be analyzed via a detailed CFD model. However, this approach (if done properly) requires a good insight into fluid mechanics, the specification of many parameters, is time-consuming to set up and computationally intensive. It is difficult, using this approach, to make parametric studies as even small changes in, for example, geometry can require a major effort in reworking the input.

A nodal network model takes a more aggregated physical approach to the modeling problem. If a suitable simulation environment is available, such models can be set up quickly, need less parameters and will execute faster. The models are also capable, in principle at least, of being integrated into whole-building simulations.

The objective of the present work was to compare the performance of a component-based model of a double skin facade with a rigorous CFD simulation that combined airflow, conduction, convection and radiation. Further comparison was made with an extensive set of experimental measurements made on a prototype facade which had been tested in a solar simulator.

\section{MODELING METHODOLOGY}

\subsection{Approach}

The flexibility afforded by adopting a modular simulation approach has been recognised for several decades. Early modular environments included TRNSYS (SEL 2000) and HVACSIM+ (Park 1985), to which have been added, for example, SPARK (Sowell et al 1986), IDA (Sahlin et al 1991) and Matlab/Simulink (Mathworks 2002). The choice of simulation environment is important, as code portability between environments is generally difficult. A notable exception to this is the Neutral Model Format (NMF) (Sahlin et al 1989) which, together with the pioneering ASHRAE NMF Translator, meant that models written in NMF could be run under IDA, TRNSYS and HVACSIM+ environments.

Additional flexibility and functionality is obtained if component models are written in an input/outputfree formulation. If a suitable solver is available, this avoids the creation of multiple models of the same component and facilitates the simultaneous solution of fluid flow with thermodynamic equations. In addition, input/output-free modeling copes very effectively where the system information flow network (graph) is highly connected, leading to a significant number of cycles in the system graph. These are sometimes referred to as algebraic loops and can cause numerical difficulties with some programs.

The approach taken in this work was to define a set of individual component models which were used to simulate, in the first instance, the performance of the prototype facade for which experimental test data were available, but which could then easily be reconfigured for any alternative facade design. A key aspect of this approach was the simultaneous solution of the thermal processes and the buoyancy-driven flow in the facade: the former were handled by established calculation procedures taken from the literature, the latter by balancing the buoyancy forces generated by heat transfer to the air in the cavity with the hydraulic resistance to the resulting flow. The problem was formulated as a dynamic model so that in future work control performance could be investigated.

\subsection{Simulation environment}

It was decided to use the open-source simulation environment Octave (Eaton 2006) in this research. 


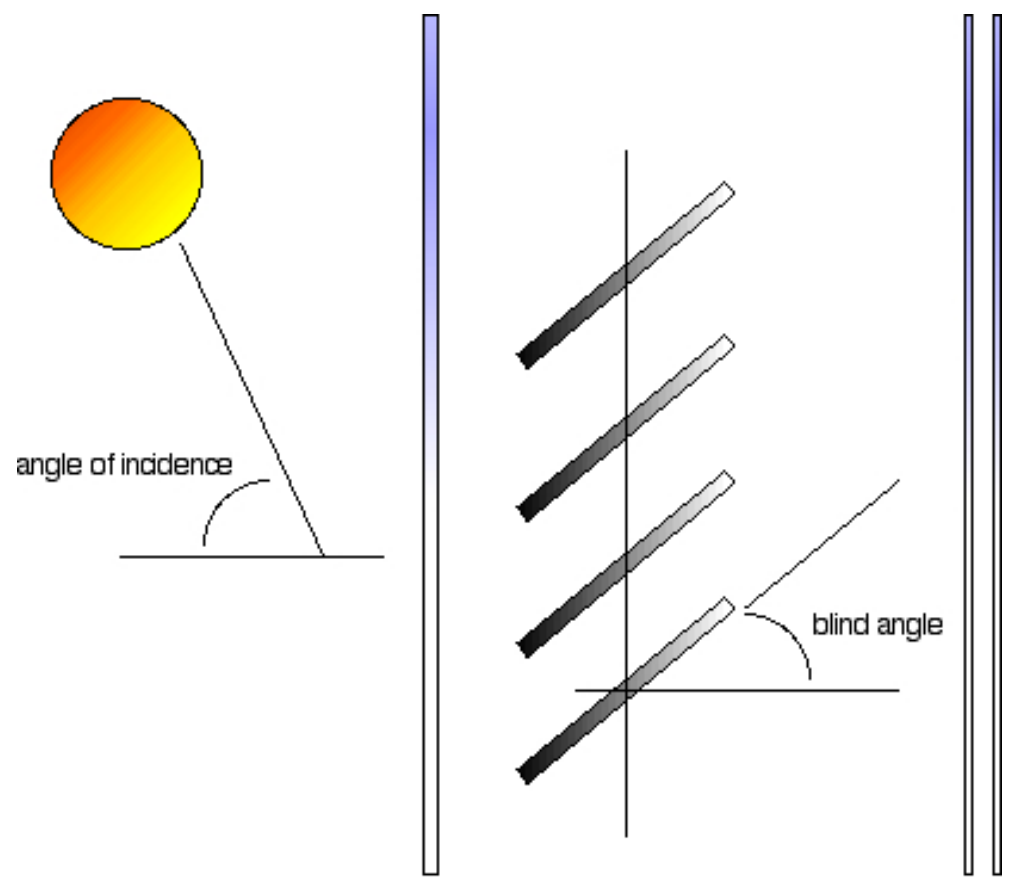

Figure 1: Arrangement of the major facade components

The reasons for this decision can be summarised:

- the program is freely available on a wide variety of platforms;

- there is an active developer base which is coordinated by the program originator;

- it is an interpreted language which facilitates rapid model (function) development;

- numerically intensive procedures can be compiled from Fortran, $\mathrm{C}$ or $\mathrm{C}++$ code and subsequently called as native functions;

- graphics routines, based on Gnuplot, are callable from within the code;

- the code has a high compatibility with Matlab.

There is also built-in access to a wide range of open-source numerical libraries, including differential and differential/algebraic (DAE) equation solvers such as LSODE, DASSL and DASPK which permit the use of input/output-free modeling, greatly facilitating the simultaneous solution of heat transfer and buoyancy-driven flow in the facade. Given the essentially two-dimensional nature of the problem, the facade was discretized vertically, using sections around $600 \mathrm{~mm}$ high, thus maintaining compatibility with the experimental data.

\subsection{Component models}

The general arrangement of the prototype model facade, including the key geometrical parameters is shown in Fig 1.

2.3.1 Transmission/reflection at a glass surface. Reflection from a glass surface was modeled by an empirical equation derived from published data (Markus 1980). The approach assumed a constant 
value of reflectivity up to an angle of incidence $(\theta)$ of $40^{\circ}$; at higher angles a third-order polynomial was used to compute the transmitted fraction. This function for the glass used in the prototype facade is shown in Fig 2.

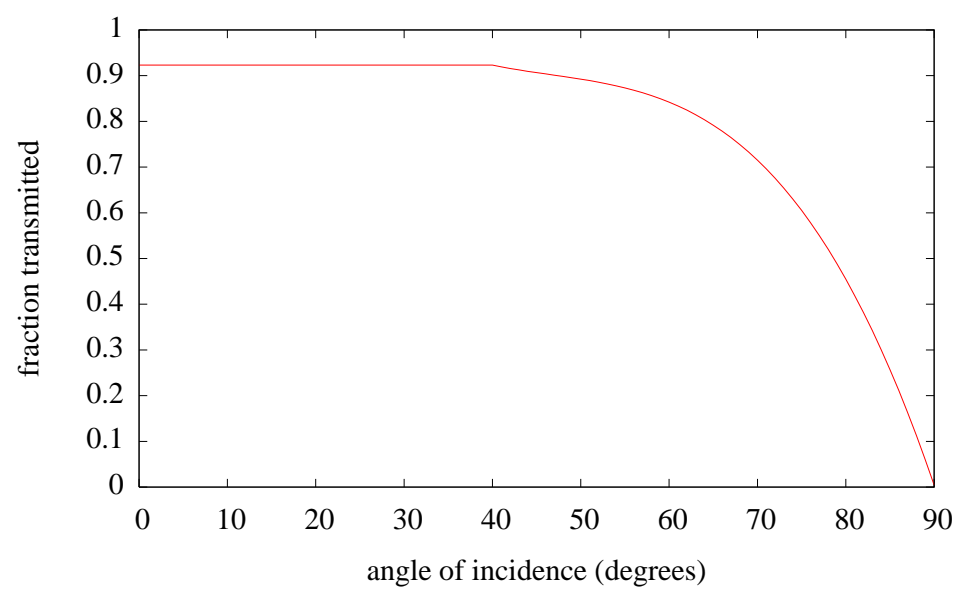

Figure 2: Absorption/reflection at glass surface

2.3.2 Absorption of radiation by glass pane. Absorption of both forward and backward (reflected) beams in the glass panes was calculated by working out the path length $z$ from the thickness of the pane, the angle of incidence and the refractive index of the glass, then applying the Beer's law relationship

$$
I=I_{o} \exp (-\alpha z)
$$

Values for the absorption coefficient $\alpha$ used in the nodal model were calculated from the database of the program Window (Lawrence Berkeley National Laboratory, 2005), giving values around $30 \mathrm{~m}^{-1}$. A maximum of two reflected beams was taken into account.

2.3.3 Nodal energy balance. A temperature node was placed at the centre of each pane of glass. There were thus equal conductances from the node to the glass surfaces. The energy balance (expressed in residual format) for each glass node was

$$
\operatorname{fvec}(i)=\dot{t}_{i}-\frac{q}{c_{i}}+\frac{k}{c_{i}}\left(t_{i}-t_{i-1}\right)+\frac{k}{c_{i}}\left(t_{i}-t_{i+1}\right)
$$

2.3.4 Surface energy balance. A steady-state energy balance was made on a surface temperature node which equated heat transfer to the surface (which could be by conduction from an adjacent material node and/or surface absorption of radiation) with long-wave radiation to visible surfaces and convection to the adjacent air.

$$
\operatorname{fvec}(i)=-q+h_{c}\left(t_{i}-t_{a}\right)+h_{r}\left(t_{i}-t_{s}\right)
$$

2.3.5 Cavity air energy balance. The air in the cavity was treated as well-mixed within a zone defined by the discretized height of the facade section. Separate convective heat transfer coefficients were used to calculate the heat transfer to the air node from the adjacent surfaces.

$$
\operatorname{fvec}(i)=\rho V c_{p} \dot{t}_{i}-h_{c, 1} A\left(t_{i-1}-t_{a}\right)-h_{c, 2} A\left(t_{i-1}-t_{a}\right)-\dot{m} c_{p}\left(t_{a}-t_{o}\right)
$$


The calculation of cavity air temperature by the nodal model produces a single bulk temperature for the discretized segment of facade in use: this is in contrast to the CFD model which, of course, provides local temperatures and velocities for each cell.

2.3.6 Transmission by blind. Several researchers have investigated the transmission of solar radiation by venetian blinds, some in considerable detail. A compromise with regard to complexity was needed here, so blind transmission was based on the approach developed by Pfrommer et al (1996). Their model was developed as a suitable algorithm to be incorporated within building energy simulation programs. The transmission was regarded as a one-dimensional process with the following components:

direct transmission through the gaps between the slats. The net open fraction will vary from 1 when the blind is parallel to the beam, to a value of $\left(1-\frac{d \sin \theta}{x}\right)$ where $d$ is the width of the blind, $x$ the slat vertical separation and $\theta$ the angle between the beam and the slat.

Specular internal reflection will occur with $n$ internal reflections increasing with the width of the slat and the angle of incidence. In general, the reflected transmittance is given by

$$
\tau=\sum_{i} r^{n} P_{i}
$$

where $r$ is the slat reflectance and $P$ the portion reflected for each $n$.

Direct-to-diffuse reflection was calculated using the 'shining factor' method of Ward (1992) but the calculation of this component was limited to the first two reflections.

Fig 3 shows the total transmission of solar radiation as a function of blind angle for a facade consisting of $12 \mathrm{~mm}$ outer glass skin, blind together with a double-glazed inner skin of $6 \mathrm{~mm}$ glass panes. The blind had a slat width of $80 \mathrm{~mm}$, slat vertical separation of $72 \mathrm{~mm}$, reflectivity of 0.2 and shining factor of 0.32 .

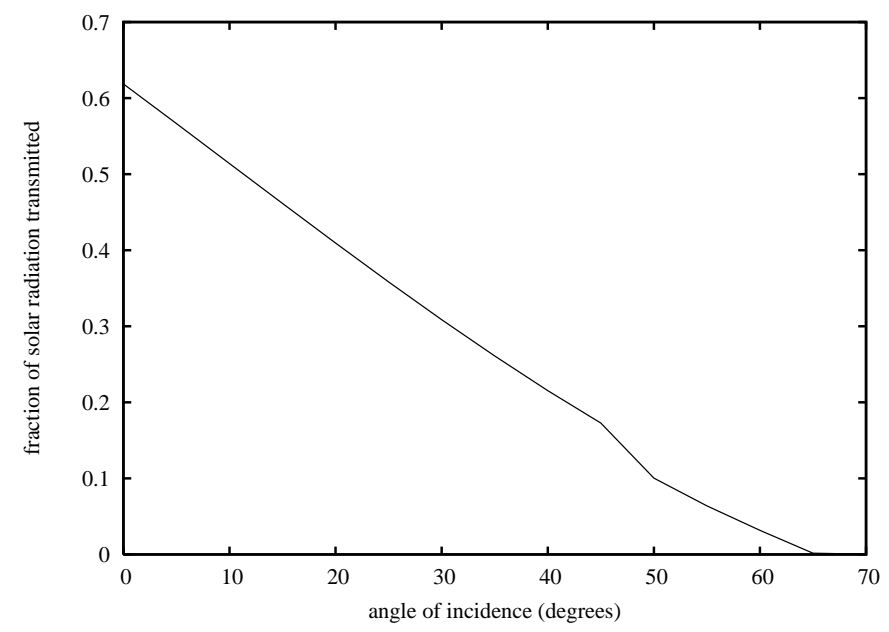

Figure 3: Solar transmission of double-skin facade with blind 
2.3.7 Convective heat transfer coefficients. Separate treatment was made for the convective heat transfer coefficient on the outer and inner surfaces of the facade. The prototype facade was exposed to still air in the laboratory and the Grashof number for this situation was generally $>10^{8}$ hence the following equation (CIBSE 1986) was used.

$$
N u_{L}=\frac{0.03(G r)_{L}^{0.4}(P r)^{0.47}}{\left[1+0.5(P r)^{0.67}\right]^{0.4}}
$$

There have been many papers reporting correlations for natural convection in channels, with both symmetrical and asymmetrical heating of the air. These include Cheng and Muller (1998), Sparrow et al (1980), Sparrow and Azevedo (1984), Klan (1976), Rohsenow (1998) and Bar-Cohen (1994). Clearly, the situation in the prototype facade represents a flow heated on each side, but output from the CFD analysis indicates that the temperature boundary layer at the top of the cavity is thin compared to the cavity width, hence single-sided heating could be regarded as a reasonable basis for the selection of an appropriate correlation. A comparison of the correlations cited above is shown in Fig 4. The shapes of the curves are broadly similar, but there is a considerable variation in their absolute values. These correlations were coded up as functions to allow changes to the internal heat transfer coefficients to be investigated.

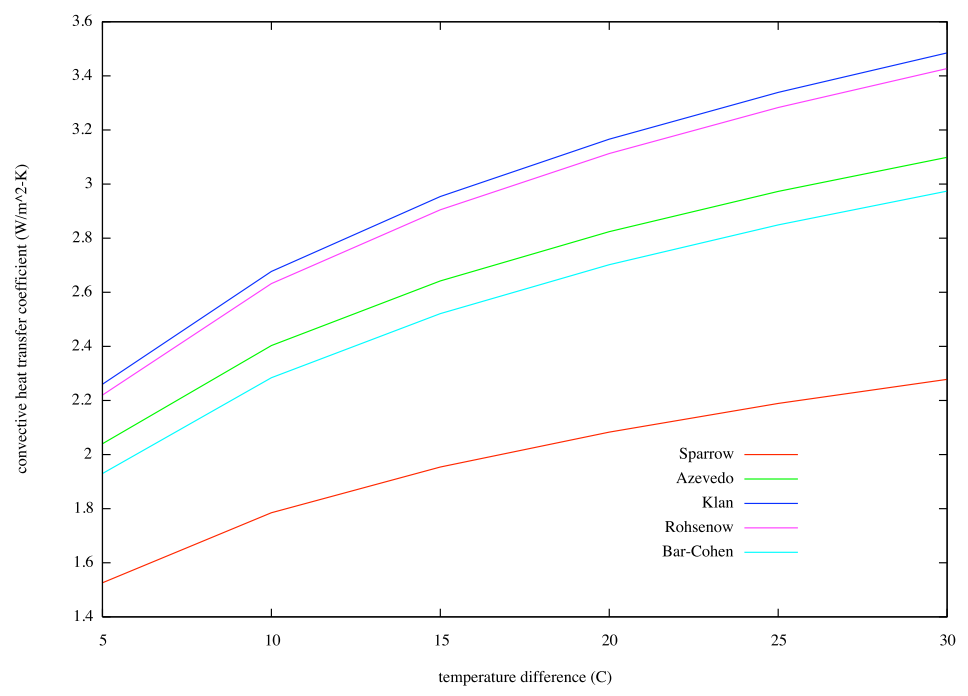

Figure 4: Convective heat transfer correlations

2.3.8 Radiation heat transfer. Radiative heat transfer was linearised by firstly calculating explicitly a radiation coefficient from the surface properties and temperatures, then using this in a linear system equation. This approach was adopted to avoid numerical problems in solving the large set of simultaneous equations. The radiation coefficient was given by

$$
h_{r}=\sigma\left(T_{1}+T_{2}\right)\left(T_{1}^{2}+T_{2}^{2}\right)
$$

so the radiation heat transfer equation was

$$
Q_{r}=\epsilon_{12} F_{12} A h_{r}\left(t_{1}-t_{2}\right)
$$

The emissivity factor was given by

$$
\epsilon_{12}=\frac{\epsilon_{1} \epsilon_{2}}{\left(\epsilon_{1}+\epsilon_{2}\right)+\epsilon_{1} \epsilon_{2}}
$$


The view factor $F_{12}$ was taken as unity for the facade - environment, elswhere it was calculated as two parallel planes of area $A_{1}$ and $A_{2}$. In the case of a partially-open blind, the projected area of the blind was used.

2.3.9 Air flow. The calculation of the air flow rate is based on the approach of Brinkworth et al (2000). The method solves a one-dimensional loop equation, in which the buoyancy force generated by heat transfer to the air is balanced by the hydraulic (entry, exit and friction) resistance of the channel. The expression used in this work is given below.

$$
\dot{m}^{3}=\frac{2 S\left(\rho_{0} A_{c}\right)^{2} g L \beta q \sin \psi}{c_{p}\left(K_{f 1}+K_{f 2}+f\left(\frac{L}{D}\right)\right)}
$$

This is an implicit formulation as the friction factor is flow rate dependent. This was handled by a local iteration (typically three were needed) rather than passing the iteration through to the solver. The stratification parameter $S$ was chosen to give an exponential temperature distribution with height.

The formula is based on the hydraulic diameter of the cavity: when a blind was present this was treated as two cavities, the hydraulic diameter of each being a function of the blind angle. Clearly this is a significant simplification, since both CFD calculations and experimental observations show that the air flow is complex, with air flow through the blind depending strongly on its angle. Simplifying this situation to a form which could be incorporated into the simplified modeling scheme would be a challenging task which time did not permit investigation.

\section{CFD SIMULATIONS}

The CFD simulations were carried out using the commercial code CFX5.7.1 (Ansys 2005). The model was assembled in several stages to allow the output to be compared to previous work of other researchers. The stages were:

1. natural convection from a vertical surface (Ostrach 1951);

2. convective and radiation heat transfer from a window with venetian blind (Machin et al 1998);

3. natural convection and radiation in a channel with heated wall (Cheng and Muller 1998).

It was found that the viscous sub-layer could not be adequately resolved using the traditional wall function approach: this was overcome using the k-omega model of Wilcox (1986). Initial simulations of a window with venetian blind (Marjanovic et al 2005) showed that a three-dimensional representation was necessary to capture all the flow characteristics. However, in order to model accurately the heat transfer through the individual glazing and blind slat elements a very fine mesh was necessary, hence it was not possible to implement this model in 3-D due to the limitations of available hardware. Convergence was achieved by first running in steady-state mode and using this result as an initial condition for transient simulation.

The radiation calculation was carried out by the Monte Carlo method. A two-band solar spectrum was used, separated at 2.7 microns wavelength. The absorption coefficients for the glass used in 
the CFD simulations were taken from the work of Safer et al (2005), namely $10 \mathrm{~m}^{-1}$ for the solar band and $3000 \mathrm{~m}^{-1}$ for the thermal band.

\section{RESULTS}

\subsection{Facade without blind}

The prototype facade was constructed to be typical of a common design of ventilated facade and had a height of $1.9 \mathrm{~m}$, width $1.28 \mathrm{~m}$ and a cavity depth of $0.55 \mathrm{~m}$. Blinds could be suspended at various locations within the cavity. The outer skin was a single pane of armoured $12 \mathrm{~mm}$ glass, the inner pane was double-glazed, with each pane consistiing of $6 \mathrm{~mm}$ glass. Surface temperatures were measured with thermocouples and air temperatures with shielded thermocouples. Air velocities were measured with omnidirectional heated sphere anemometers. All measurements were done with a vertical facade and zero angle of incidence of the solar beam. A D65 solar spectrum of air mass 1.5 was provided by an array of 15 solar simulation lamps. The front of the facade could be exposed to chosen temperatures in the range $10^{\circ} \mathrm{C}$ to $30^{\circ} \mathrm{C}$. A compartment at the back of the facade offered separately-controllable thermal conditions.

The dynamic simulation of the facade without blind is shown in Fig 5 for irradiation of 715 $\mathrm{W} / \mathrm{m}^{2}$ together with front and back temperatures of $20^{\circ} \mathrm{C}$. The absorption coefficient for the glass was $10 \mathrm{~m}^{-1}$ and the cavity heat transfer coefficients were calculated from the correlation of Rohsenow. It can be seen that the system has a time constant of about 1 hour, and that the highest surface temperature is the cavity-side face of the outer skin of glass.

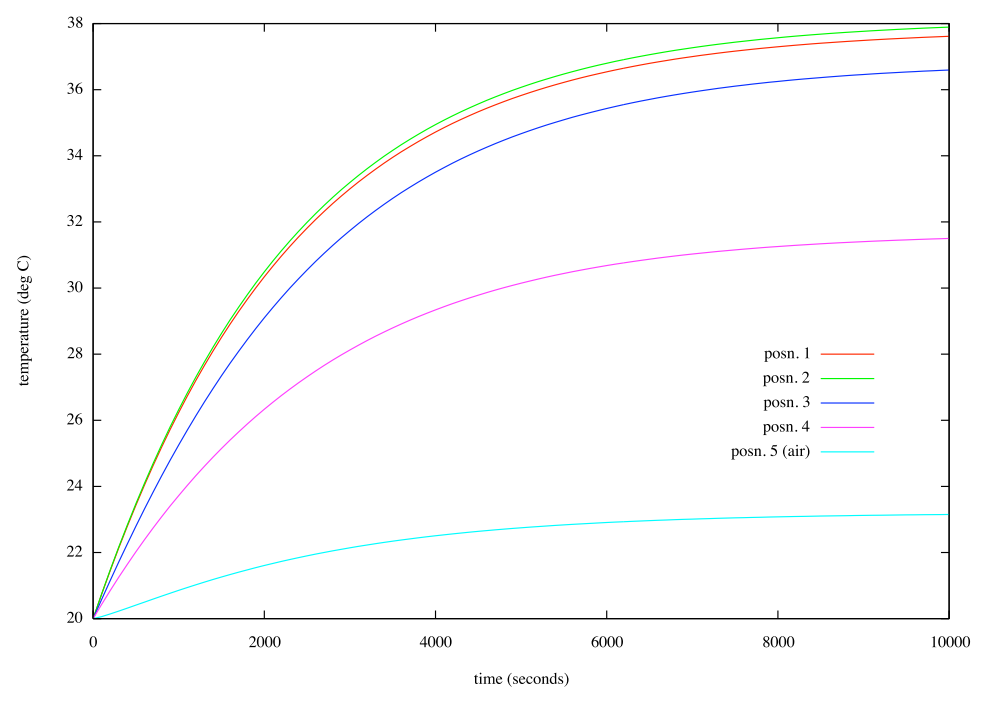

Figure 5: Dynamic simulation of facade without blind

The temperature distribution across the facade without blind is compared with the experimental results for the above conditions in Figure 6. The glass absorption coefficient was $30 \mathrm{~m}^{-1}$ taken from the available data for the float glass used in the prototype facade.

It can be seen that the comparison is satisfactory, the temperatures are those prevailing near the top of the facade, the experimental value shown is the average of the five readings taken across the cavity. 


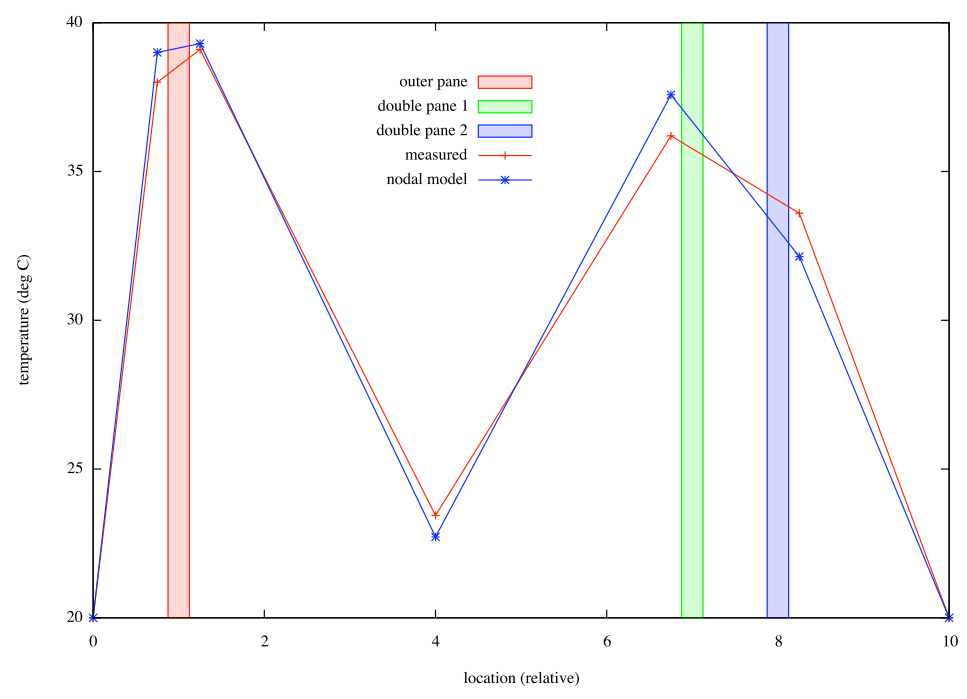

Figure 6: Temperature distribution across facade without blind (1)

The equivalent comparison with CFD output is shown in Fig 7. The comparison was made under the same conditions as above, excepting that a value for the glass absorption coefficient of $10 \mathrm{~m}^{-1}$ was adopted in accordance with that used in the CFD model. Again, agreement is good although the CFD model predicts a rather higher surface temperature on the 'room' side of the double glazing, suggesting that there is some difference between the two heat transfer calculations at this point.

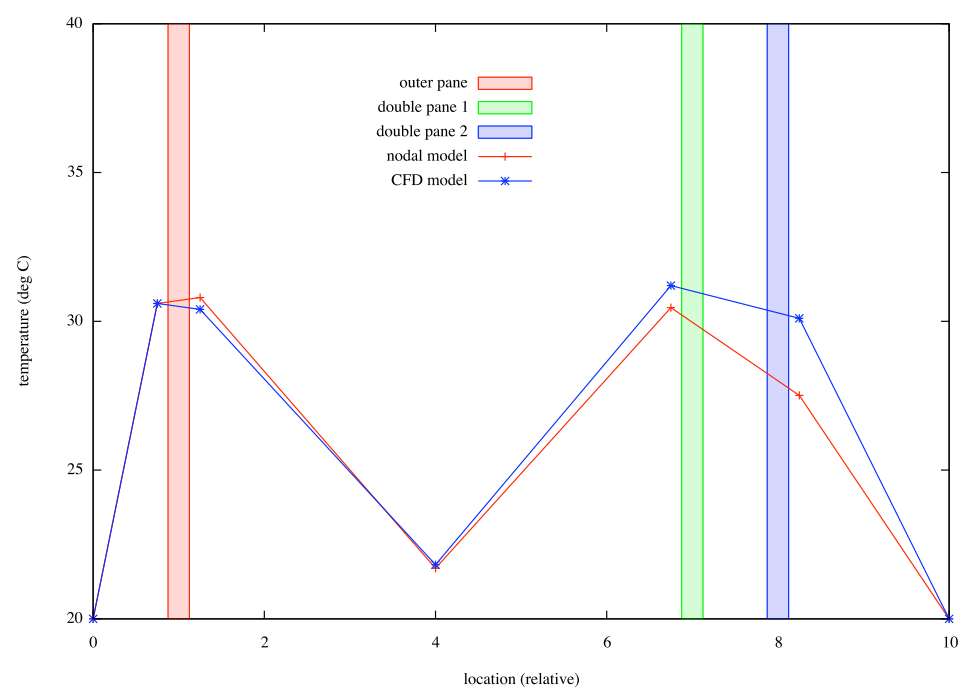

Figure 7: Temperature distribution across facade without blind (2)

\subsection{Facade with blind}

The temperature distributions across the facade predicted by the nodal and measured in the solar simulator is shown in Fig 8 and a comparison of the nodal model with the CFD calculations is given by Fig 9 . 


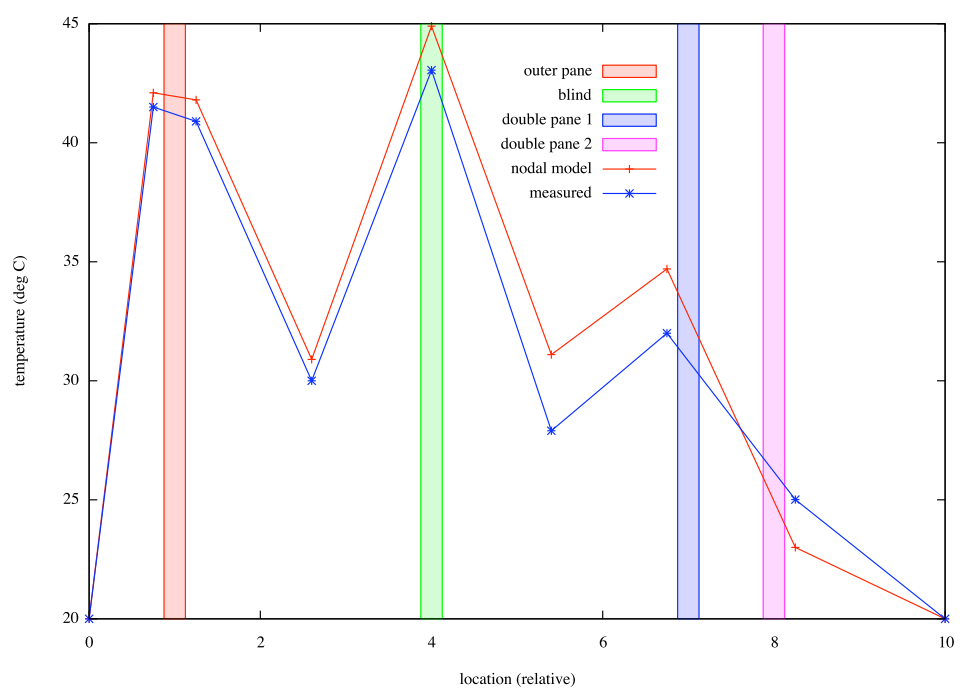

Figure 8: Temperature distribution across facade with blind (1)

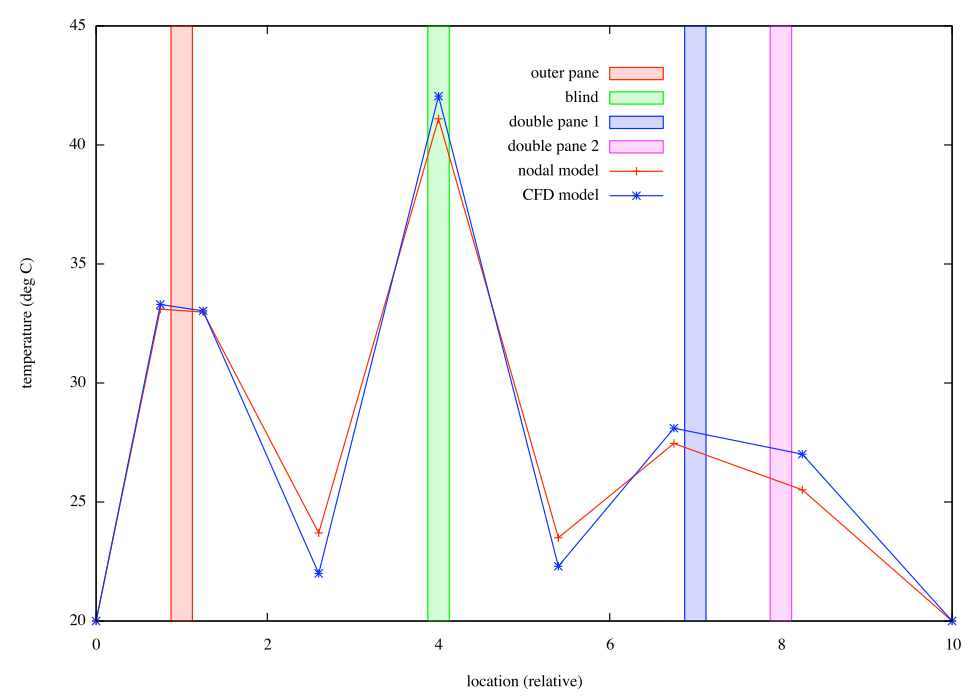

Figure 9: Temperature distribution across facade with blind (2)

\subsection{Air velocities in the cavity}

The prediction of air velocities arising from buoyancy-driven flow is the area where the largest divergencies between the models and the experimental results would be expected, and this proved to be the case. A comparison of the predicted velocities (averaged across the top of the cavity) is given in Table 1. The conditions under which this comparison is made are as before. The blind had an emissivity of 0.7 , was located mid-cavity (the horizontal location of the blind was found to be fairly insensitive) and the blades were at an angle of $45^{\circ}$.

It is not a simple matter to decide what constitutes good agreement with such weakly-driven flows. It is certainly possible to say that agreement is reasonable in that responses to changes in operating conditions are in line with expected behaviour in all cases, hence both models give credible results. Potential sources of error would include 


\begin{tabular}{|l|l|l|}
\hline & no blind & with blind \\
\hline nodal model $\left(10 \mathrm{~m}^{-1}\right)$ & 0.075 & 0.12 \\
CFD & 0.152 & 0.20 \\
nodal model $\left(30 \mathrm{~m}^{-1}\right)$ & 0.083 & 0.175 \\
measured & 0.106 & 0.24 \\
\hline
\end{tabular}

Table 1: Comparison of mean air velocities $\left(\mathrm{m} \mathrm{s}^{-1}\right)$ at top of cavity

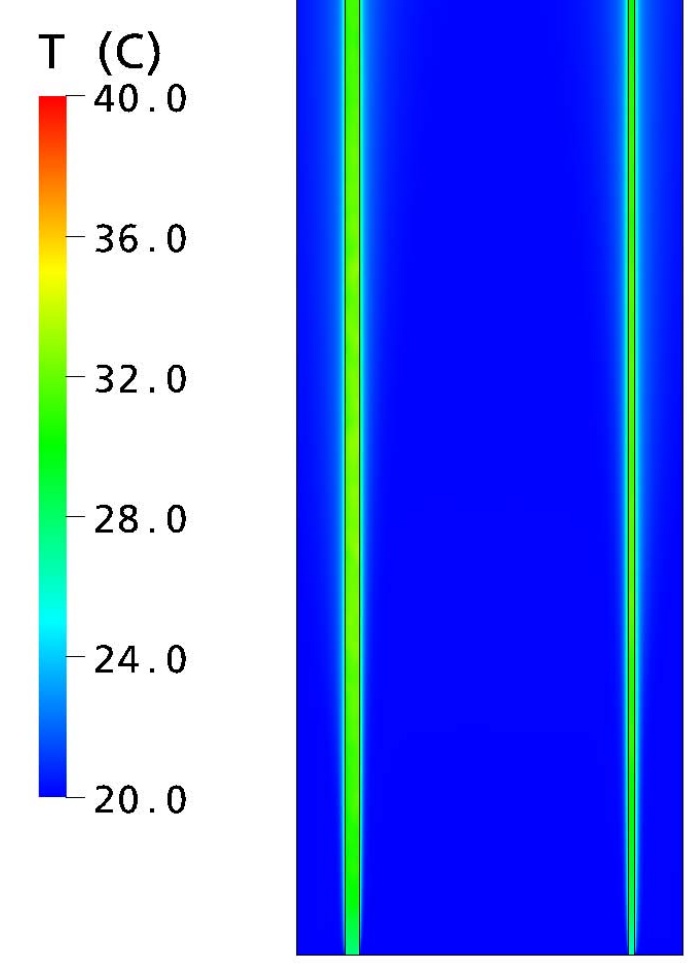

Figure 10: Temperature distribution without blind

- the hydraulic resistance terms in the nodal model are standard engineering pressure drop values, which have been derived mainly for design purposes;

- room air flows could have affected the anemometer readings, especially at low levels in the facade;

- the boundary conditions specified in the CFD model may not corrrespond to the conditions in the laboratory.

\subsection{CFD model output}

Figure 10 shows the temperature distribution within the air and glass (here the single pane is on the right-hand side). It can be seen that the temperature boundary layer is still very thin at the top of the cavity, indicating that little mixing has taken place in the horizontal plane.

The velocity and temperature fields for the case of cavity with blind are shown in Figs 11 and 12, 


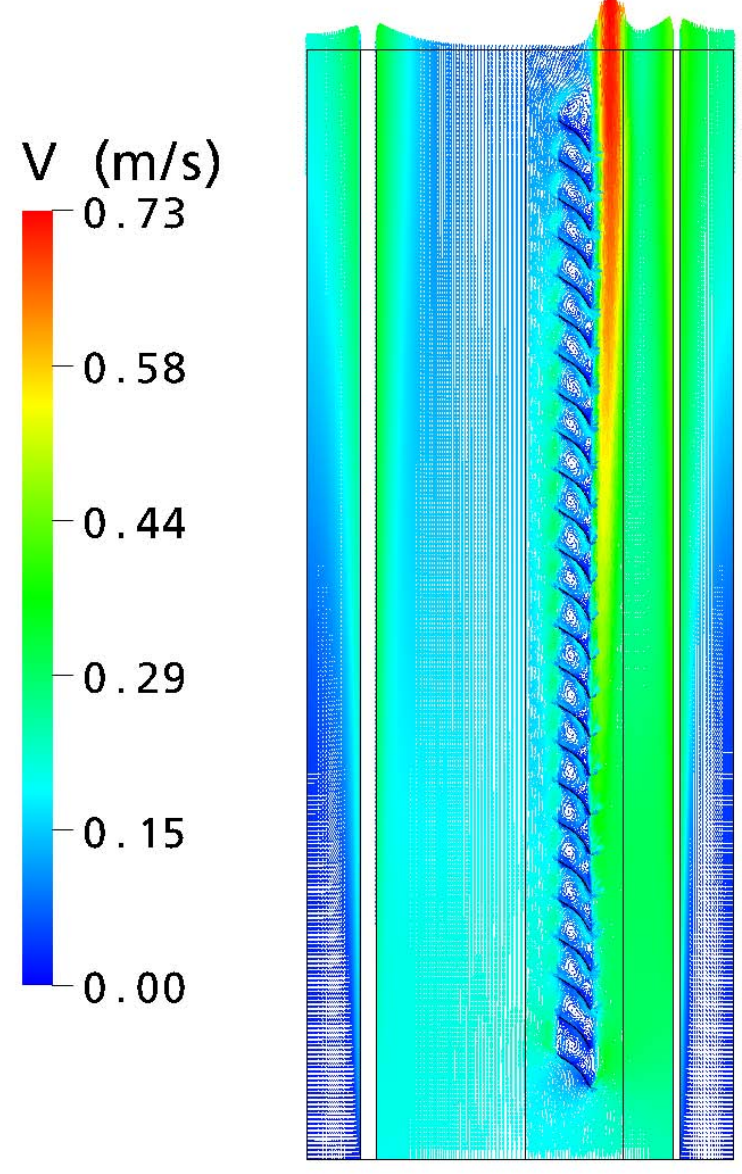

Figure 11: Velocity distribution with blind

respectively. The strong thermal plume originating from the blind can clearly be seen, together with the turbulent flow around the blades.

\subsection{Sensitivity analysis}

One of the benefits of a nodal model is that it affords an opportunity to examine the sensitivity of the solution to parameters which are subject to some uncertainty. This was carried out for the scenario described above with respect to the absorption coefficient of the glass and the convective heat transfer coefficient in the cavity. The film coefficient was varied by linearly scaling the calculated value, in this case from the correlation of Rohsenow. This scaling method is reasonable as Figure 4 shows that all the correlations investigated had similar characteristic shapes.

Figure 13 shows the fractional change in heat transfer to the air in the cavity as a result of varying the two stated parameters. It can be seen that the result is more sensitive to choice of glass optical properties than to convective heat transfer. Figure 14 shows the fractional change in mean velocity of the air as a function of the same parameters. Again, it can be seen that the optical properties of the glazing are more influential than the heat transfer coefficient. 


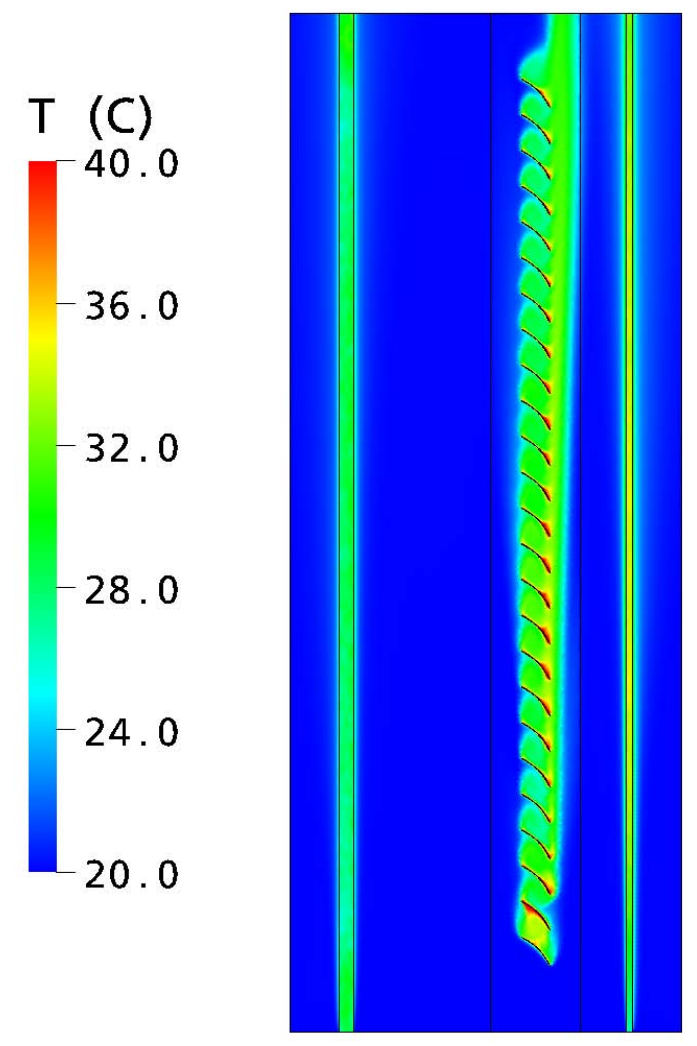

Figure 12: Temperature distribution with blind

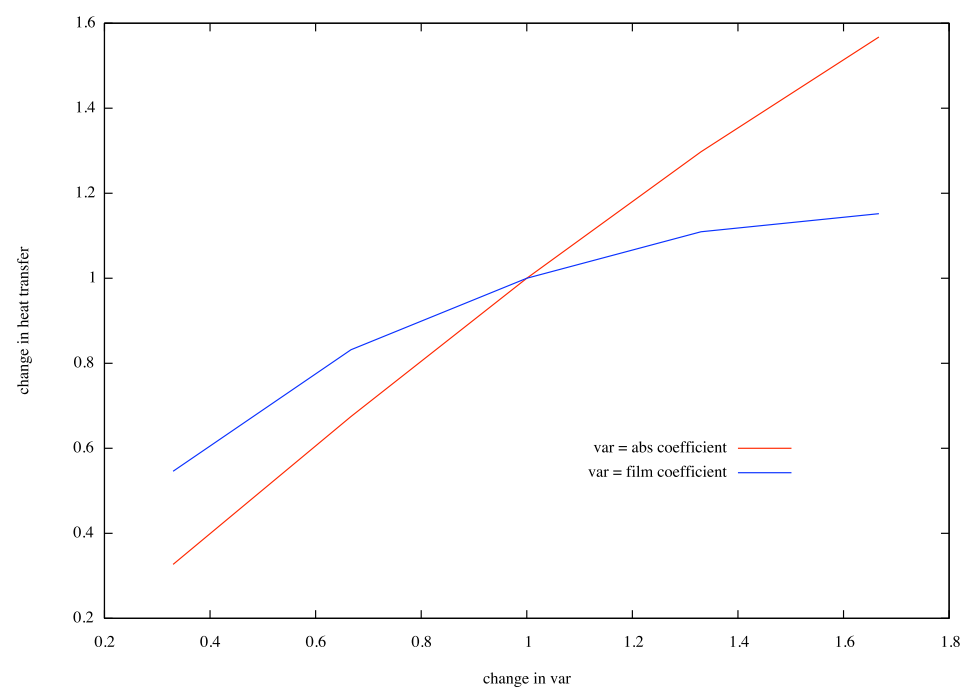

Figure 13: Sensitivity of heat transfer in the cavity 


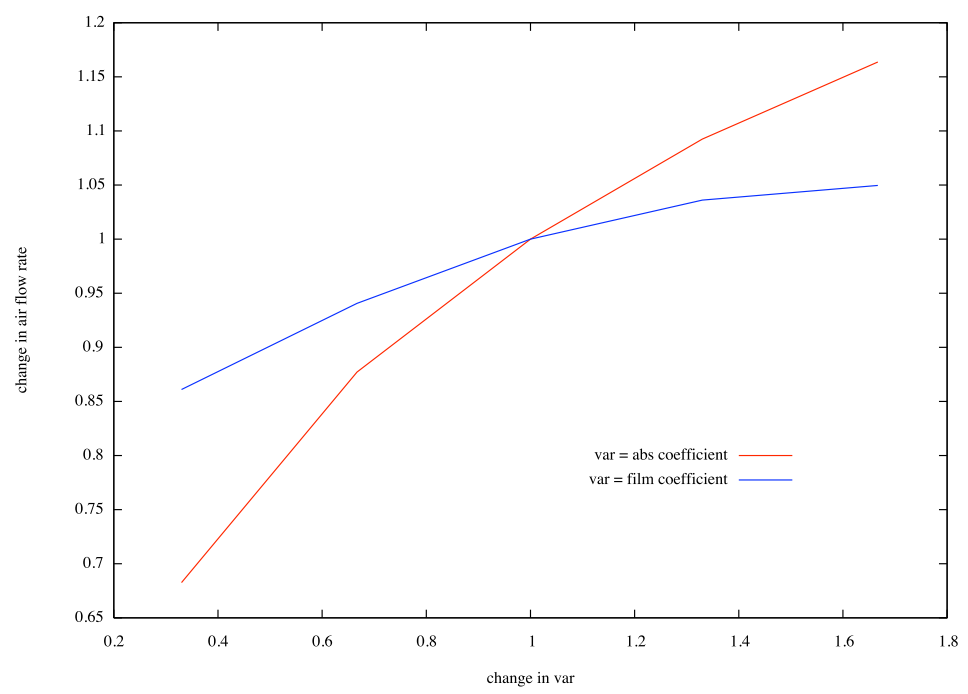

Figure 14: Sensitivity of air velocity in the cavity

\section{CONCLUSION}

Component models have been developed to enable a dynamic nodal network simulation of a doubleskin facade to be constructed. The simulation enables the simultaneous solution of both heat transfer and buoyancy-driven flow within the cavity. The models were implemented in the opensource simulation environment Octave and the equation set solved using the differential-algebraic solver DASSL. This semi-empirical approach allows much of the detailed physics of the performance of the facade to be examined, hence it sits between the rigorous field problem formulation of CFD analysis and the empirical approach used in earlier work.

The temperatures calculated by the nodal model agreed well with both CFD predictions and with experimentally-determined results. The feasibility has been demonstrated of simultaneous solution of heat transfer and buoyancy-driven flow in the facade by a component-based approach and the air velocities predicted by this means are credible.

The output from modeling a prototype facade was compared with that obtained from a CFD analysis which included radiation heat transfer. This showed that, in the case of global rather than spatially-resolved quantities, generally good agreement between the two modeling approaches was obtained. It can be concluded that useful results could be obtained from the nodal network approach. Its inherent simplicity, modest input data requirements, together with low computational demands, means that it could be developed into a tool useable by designers. 


\section{NOMENCLATURE}

\begin{tabular}{|c|c|c|c|c|c|}
\hline$A$ & area & $m^{2}$ & Greek & & \\
\hline 11 & thermal capacitance & $\mathrm{J} \mathrm{kg}^{-1}$ & $\alpha$ & absorption coefficient & $\mathrm{m}^{-1}$ \\
\hline$c_{p}$ & specific heat & $\mathrm{J} \mathrm{kg}^{-1} \mathrm{~K}^{-1}$ & $\beta$ & expansion coefficient & $\mathrm{K}^{-1}$ \\
\hline$d$ & blind width & $\mathrm{m}$ & $\epsilon$ & emissivity factor & - \\
\hline$D$ & channel width & m & $\psi$ & angle to horizontal & degrees \\
\hline$f$ & friction factor & $\mathrm{m}$ & $\rho$ & density & $\mathrm{kg} \mathrm{m} \mathrm{m}^{-3}$ \\
\hline fvec & vector of residuals & - & $\sigma$ & Boltzmann constant & $\mathrm{W} \mathrm{m}^{-2} \mathrm{~K}^{-4}$ \\
\hline$F$ & view factor & - & $\theta$ & blind angle & degrees \\
\hline$g$ & gravitational constant & $\mathrm{m} \mathrm{s}^{-2}$ & $\tau$ & transmittance & - \\
\hline$h$ & heat transfer coefficient & $\mathrm{W} \mathrm{m}^{-2} \mathrm{~K}^{-1}$ & Subscripts & & \\
\hline$i$ & integer & - & 1 & inlet & \\
\hline$I$ & radiation intensity & $\mathrm{W} \mathrm{m}^{-2}$ & $\begin{array}{l}1 \\
2\end{array}$ & & \\
\hline$k$ & thermal conductance & $\mathrm{W} \mathrm{K}-1$ & 2 & outlet & \\
\hline$K$ & inlet pressure loss factor & - & $a$ & alr & \\
\hline$L$ & length (height) of channel & $\mathrm{m}$ & $c$ & convection & \\
\hline$\dot{m}$ & mass flow rate & $\mathrm{kg} \mathrm{s}^{-1}$ & $O$ & ambient & \\
\hline$n$ & integer & - & $r$ & radiation & \\
\hline$q$ & heat flux & W & $s$ & surrace & \\
\hline$r$ & reflectance & - & & & \\
\hline$S$ & stratification factor & - & & & \\
\hline$t$ & temperature & $\mathrm{C}$ & & & \\
\hline$T$ & temperature & $\mathrm{K}$ & & & \\
\hline$V$ & volume & $\mathrm{m}^{3}$ & & & \\
\hline$x$ & blind vertical separation & $\mathrm{m}$ & & & \\
\hline$z$ & path length & $\mathrm{m}$ & & & \\
\hline
\end{tabular}




\section{REFERENCES}

Ansys 2005 Ansys CFX 2005, version 5.7.1, user manual.

http://www.ansys.com/cfx/

Bar-Cohen, A and W M Rohsenow 1984. "Thermally optimum spacing of vertical, natural convectioncooled parallel plates" ASME Journal of Heat Transfer 106:116-123.

Brinkworth, B J, R H Marshall and Z Ibarahim 2000. "A validated model of ventilated PV cladding" Solar Energy 69(1):67 - 81.

Chartered Institution of Building Services Engineers 1986. "CIBSE Guide Book C (Heat Transfer)" CIBSE: London.

Cheng, X and U Muller 1998. "Turbulent natural convection coupled with thermal radiation in large vertical channels with asymmetric heating" International Journal of Heat and Mass Transfer 41(12):1681-1692.

Eaton, J W 2006. Gnu Octave - a high level language. University of Wisconsin-Madison, USA. http://www.gnu.org/software/octave/

Fux, V 2006. "Thermal simulation of ventilated PV facades" PhD thesis, Loughborough University, UK.

Klan, H 1976. "Free convection in heated vertical channels" Dissertation, Technische Hochschule Darmstadt.

Klein, S A et al 2000. "TRNSYS - a transient system simulation program" Solar Energy Laboratory, University of Madison-Wisconsin, USA.

Lawrence Berkeley National Laboratory, 2005. WINDOW program documentation, Berkeley, CA, USA. http://windows.lbl.gov/software/window/window.html

Marjanovic, L, M J Cook, V I Hanby and S J Rees 2005 "CFD modelling of convective heat transfer from a window with adjacent venetian blinds" Proceedings of Building Simulation 05 Montreal:IBPSA.

Markus, T A and E N Morris 1980. "Buildings, climate and energy" ISBN 0273002686 Pitman International:London.

Machin, A D, D Naylor, S J Harrison and P H Oosthuizen 1998. "Experimental study of free convection at an indoor glazing surface with a venetian blind" HVACERR Research 4(2): 153 -166.

Mathworks 2002. Matlab/Simulink user manuals. The Mathworks Inc, Natick, MA, USA.

Ostrach,S 1951. "An analysis of laminar free-convection flow and heat transfer about a flat plate parallel to the direction of the generating body force". NACA Report 111, available on http://naca.larclnasa.gov

Park, C, D R Clark and G Kelly 1985. "An overview of HVACSIM+, a dynamic building/HVAC/control 
simulation program" Proceedings of Building Simulation 85 IBPSA:Seattle.

Pfrommer, P, K J Lomas and CHR Kupke 1996. "Solar radiation transport through slat-type blinds: a new model and its application for thermal simulation of buildings" Solar Energy 57(2):77-91.

Rohsenow, W M, J P Hartnett and Y I Cho 1998. "Handbook of heat transfer" McGraw-Hill:New York.

Safer, N, M Woloszyn, J Rous, G Rusaouen and F Kuznik 2005. "Modelling of the double-skin facades for building energy simulations: radiative and convective heat transfer" Proceedings of Building Simulation 05 IBPSA:Montreal.

Sahlin, P and E F Sowell 1989. "A neutral format for building simulation models" Proceedings of Building Simulation 89 IBPSA:Vancouver.

Sahlin, P and A Bring 1991. "IDA solver: a tool for building and energy systems simulation" Proceedings of Building Simulation 91 IBPSA:Nice.

Sowell, E F, W.F. Buhl, A.E. Erdem, and F.C. Winkelmann 1986. A prototype object-based system for HVAC simulation Proceedings of second International Conference on System Simulation in Buildings University of Liége:Liége.

http://gundog.lbl.gov/

Sparrow, E M, S Shah and C Prakash 1980. "Natural convection in a vertical channel..." Numerical Heat Transfer 3:297-314.

Sparrow, E M, G M Chrysler and L F Azevedo 1984. "Observed flow reversals and measuredpredicted Nusselt numbers for natural convection in a a one-sided heated channel" Journal of Heat Transfer 106:325-332.

Ward, G J 1992. "Measuring and modeling anisotropic reflection" Lighting Systems Research Group, Lawrence Berkeley Laboratory, USA.

Wilcox, D C 1986. "Multiscale model for turbulent flows" In AIAA 24th Aerospace Sciences Meeting, American Institute of Aeronautics and Astronautics.

\section{ACKNOWLEDGEMENTS}

The authors would like to acknowledge financial support for this research from the Engineering and Physical Sciences Research Council, UK via grants GR/S02396/01 and GR/S02389/01. In addition, we would like to acknowledge the initial contribution of Dr Ljiljana Marjanovic to both the CFD and nodal network modeling, and our partners in the project, Ove Arup and Partners and IT Power Ltd. 